\title{
THE DEVONIAN EXPLOSION OF LIFE ON LAND: EARLY RECORDS OF BEHAVIOR FROM MARGINAL MARINE SETTINGS OF THE APPALACHIAN BASIN
}

\author{
WEGWEISER, Marilyn D., Department of Geological Sciences, The Ohio State \\ University, Columbus, OH 43210, USA.
}

Some Upper Devonian rock units from the southern Lake Erie region of the northwestern Appalachian basin contain diverse and abundant ichnofaunal assemblages that provide new information about early behavior and trophic relationships in marginal marine to nonmarine environments. Formations containing marginal marine ichnofaunal assemblages are the Venango, Chadakoin, Girard, and Bedford Formations, and coevel units, including the Catskill Formation. Strata from this region are significant for the study of the early invasion of land by arthropods, especially xiphosurans, because some of the oldest known trace fossils attributable to limulids occur in these formations. The Devonian ichnofaunal assemblages are important because they provide one of the earliest records of behavior from a variety of animals, including both invertebrates and vertebrates. A number of these trace fossils are new ichnotaxa. These strata show that tidal flats, estuaries, and other nearshore environments supported diverse animal communities by the Late Devonian.

Invertebrate traces found in these rocks include abundant bilobate traces and symmetrical trackways, asymmetrical trackways, and scratch marks. These traces suggest arthropod scavenging, resting, and concealment behavior. Concealment burrows may be a consequence of hiding and hunting behavior of both predator and prey animals. Arthropods that may have acted as trace formers are xiphosurans, eurypterids, phyllocarids, decapods, scorpions, myriapods, hexapods, and perhaps others. Gastropods, burrowing pelecypods, echinoderms, and linguloid brachiopods, whose remains are present as body fossils, also probably contributed to the diversity of the ichnofacies assemblage. Trace fossils in these Upper Devonian rocks might have been produced by any or all of these creatures, and perhaps by other taxa that a have left a poor body fossil record. Overprinting of traces makes the interpretation of some traces difficult because active bioturbators such as limulids and bottom feeding fishes can quickly obliterate all other traces.

Unusual clusters or swarms of putative arthropod traces suggest gregarious grouping, schooling or "herding," nesting and mating, or possibly, annual migration behavior. Invertebrate fossils that indicate or suggest herding behavior are extremely unusual. These trace fossil clusters result from large numbers of arthropods that perhaps gathered annually, with a predilection for swarming on truncated ripple tops of subaerially exposed, sandy, cohesive sediment.

Presumed vertebrate traces suggest scavenging, resting, hiding, predation, and locomotory behaviors. Bottom-feeding fishes could have left traces similar to those made by modern fishes during feeding and concealment. Sinusoidal mega-burrows and trails are attributed to locomotion by larger fish. 